Gut, 1966, 1, 244

\title{
Massive growth of yeasts in resected stomach ${ }^{1}$
}

\author{
IVAR BORG, FRANK HEIJKENSKJÖLD, BIRGITTA NILEHH, \\ AND LENNART WEHLIN
From the Department of Surgery, the Department of Radio-diagnostics, and the Department of Bacteriology, University of Lund, Malmö General Hospital, Malmö, Sweden

EDITORIAL SYNOPSIS Three cases are reported in which gastric resection according to the Billroth I technique was later followed by symptoms of fullness after meals and vomiting. $X$-ray examination showed a bezoar-like mass with the radiopacity of soft tissue in the remnant of the stomach in each case. Gastric aspiration produced mucous material which on microscopic examination and culture was found to be swarming with yeasts. The authors discuss the frequency and clinical significance of the condition.

As is known, yeasts often occur in the oral cavity and the gastrointestinal tract as saprophytes (Winner and Hurley, 1964). Sometimes, however, infection with Candida albicans causes thrush in the alimentary tract (Zalesky, 1864; Meixner, 1935; Craig and Farber, 1953; Beemer, Pryce, and Riddell, 1954). The most common sites of such lesions are the oral cavity and the oesophagus in infants as well as in adults. Thrush in the stomach, described as early as 1771 by $R$. von Rosenstein, and in the gut is rare. Most cases on record have been seen in debilitated infants, but the disease is occasionally also seen in adults in a poor condition. In such severe cases, infected areas of the mucosa are ulcerated and infiltrated with yeast-like cells (Zalesky, 1964; Lewis, 1933; Meixner, 1935; and others).

We have recently observed certain patients with massive occurrence of yeasts in residual stomachs after gastric resection. These cases differed clinically, radiographically, and microbiologically from those described earlier. These patients were adults and all had undergone gastrectomy according to Billroth $\mathbf{I}$. $X$-ray examination showed a bezoar-like formation in the stomach. Microscopical examination and culture of the gastric contents revealed a massive collection of yeasts. Histological examination of the gastric mucosa showed no signs of infiltration.

These patients complained of feeling of a lump in the epigastrium, early feeling of fulness at meals, and vomiting. Thus, the symptoms did not differ largely from those of postoperative cicatricial stenosis, for example. The symptoms appeared within one to a few months of the operation.

${ }^{2}$ This is a preliminary report.
Three illustrative cases are described below.

\section{METHODS OF EXAMINATION}

Samples of the gastric contents were collected through a large-bore sterile tube with the patient in the postabsorptive state. A large-bore tube was used to facilitate the removal of the viscous material, without which the sample might be less representative.

In the cases described below samples of the gastric contents were also obtained at operation. The samples were studied immediately or stored at $+4^{\circ} \mathrm{C}$. to suppress further growth of any microorganisms present.

Smears from various parts of the samples were stained by Gram's method and examined microscopically. The samples were also cultured on various media allowing growth of fungi, aerobic and anaerobic cocci, as well as spore-forming bacteria, lactobacilli, coliform bacteria, and other aerobic Gram-negative rods, but not of slowly growing anaerobic mycobacteria or slowly growing fungi.

The yeasts were classified according to conventional biochemical and morphological criteria (Lodder and Kreger-Van Rij, 1952).

Samples of gastric juice were also collected after stimulation according to Kay's method in order to assay the acidity.

Biopsy specimens of the gastric mucosa were removed at surgical exploration.

Routine barium $x$-ray examinations had been done repeatedly.

\section{CASE REPORTS}

CASE 1 H.J., a man born in 1917, in 1946 underwent gastrectomy in Germany (Billroth II) because of duodenal ulcer. He afterwards felt well until 1955, when he had a radiologically verified jejunal peptic ulcer. Bilateral vagotomy was then done. 
In August $1956 x$-ray examination revealed a recurrence of the jejunal ulcer. Three months later he developed symptoms indicating a new recurrence, but $x$-ray examination showed no evidence of any ulcer. In 1959 he spent two spells in hospital because of epigastric pain, dumping, loss of weight, and anaemia. In January 1960 he had symptoms of dumping and afferent loop syndrome and Billroth II was converted to a Billroth I. No peptic ulcer was found at operation. For five days after the operation the patient was given benzylpenicillin-procaine in a dose of 600,000 i.u. twice a day because of mild respiratory tract complications. After some months' convalescence he felt fairly well, but at the end of 1960 he complained of a feeling of epigastric fulness, and he had pain to the left of the epigastrium at meals. He could only eat small portions, and often vomited after meals. He brought up mucus with a slight admixture of food. $X$-ray examination in January 1961 showed that the stomach was markedly dilated by a mass with the radiopacity of soft tissue almost the size of a child's head (Fig. 1 a-d). The barium mixed only slightly with the mass, which was not homogenous. Some parts of it were radiolucent. Its upper surface was somewhat cupped. It shifted with the posture of the patient and appeared to be semi-fluid. No ulcer or infiltration of the stomach wall was seen. Nor were any changes seen in the stoma, through which the barium passed unhindered. Within four hours almost all of the barium reached the colon but a small amount was still adherent to the mass in the stomach.

Some sort of a bezoar was suspected and on 18 January 1961, the patient was submitted to gastrotomy which, however, revealed only a small amount of soursmelling gastric contents, a somewhat hypertrophic gastric mucosa, of which a biopsy specimen was removed, and a stoma allowing the passage of the thumb. Histological examination of the biopsy specimen showed moderate gastritis but otherwise nothing remarkable. Before the operation, however, the gastric contents had been removed by a stomach tube but had not been examined.

In February 1963 the patient was re-admitted to hospital because of persistent symptoms with epigastric tension, loss of appetite, and early feeling of fulness of the stomach with pain and vomiting after meals. $X$-ray examination again showed the same bezoar-like picture, which was largely unchanged also at repeated examinations, the last in 1965.

Histamine-stimulated secretion $(0 \cdot 1 \mathrm{mg}$. histamine $\mathrm{HCl} / 10 \mathrm{~kg}$. body weight) showed no free $\mathrm{HCl}$, but a total acidity of at most 40 c.u. On maximum histamine stimulation according to Kay's test, the secretion still showed no free $\mathrm{HCl}$ but a total acidity of $117 \mathrm{c.u}$.

Microbiological examination Samples of the gastric contents were collected on seven occasions. On six of these occasions, the samples were of the same macroscopical type: brownish, tenacious, semi-fluid, and mucous. Microscopical examination regularly showed large numbers of yeast cells everywhere in the specimen and, in some areas, abundant pseudomycelia also (Fig. 2).

Culture gave a dense growth of yeasts of two types, Candida krusei and Torulopsis glabrata. Culture for

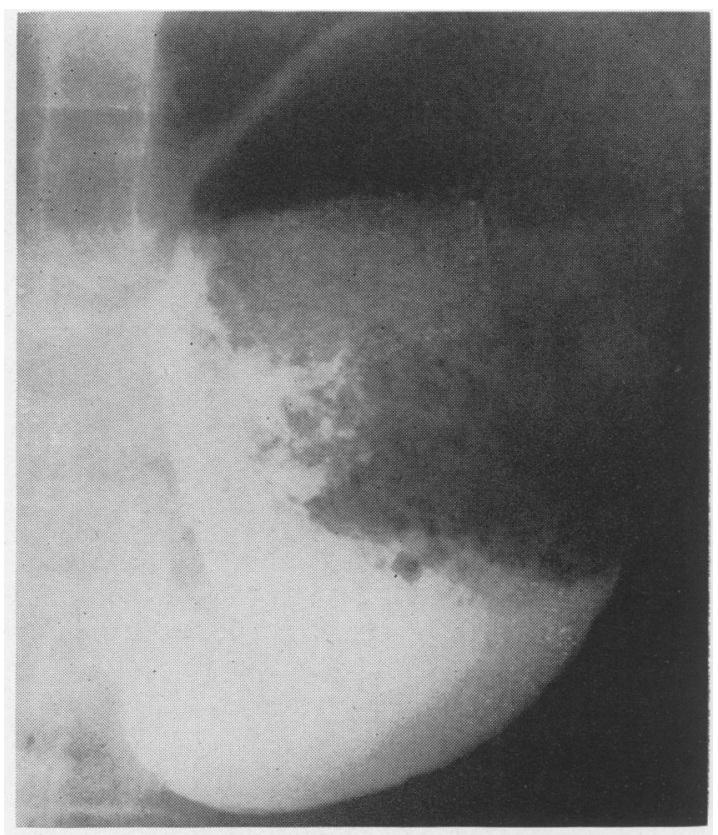

FIG. 1a.

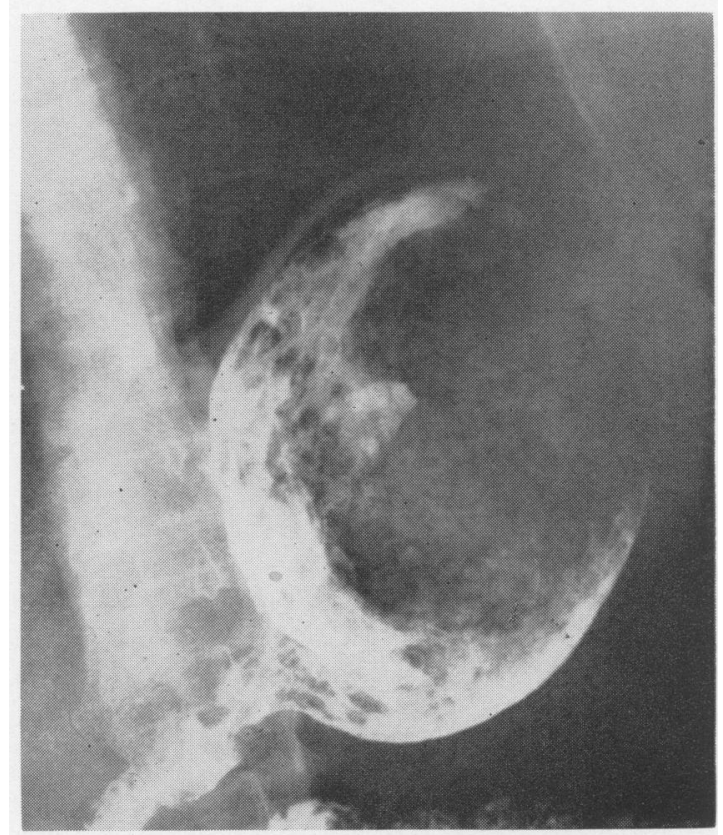

FIG. $1 \mathrm{~b}$.

FIG. 1. Case 1. Gastric remnant markedly dilated by a large bezoar-like mass. No ulcer or infiltration of the stomach wall. Normal stoma with unhindered passage of barium. (a) standing position; (b) prone position; (c) supine position. and $(d)$ left lateral position with horizontal beams. 


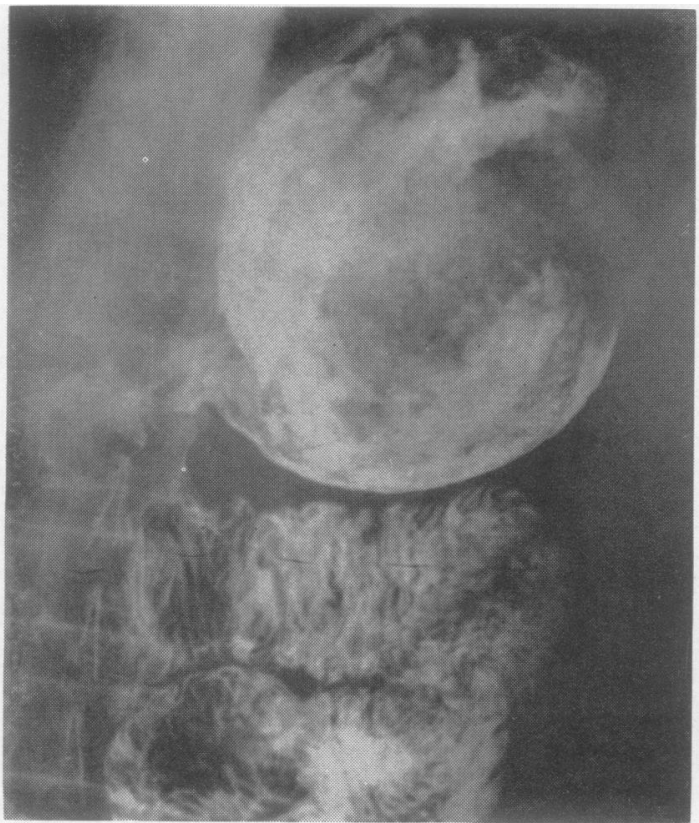

bacteria regularly gave growth of lactobacilli and sometimes also of small numbers of alpha-haemolytic streptococci and coliform bacilli. On one occasion, however, after a period of intense treatment with gentian violet lavages, the samples showed only a very sparse growth of yeasts of the same type as earlier and also on later occasions.

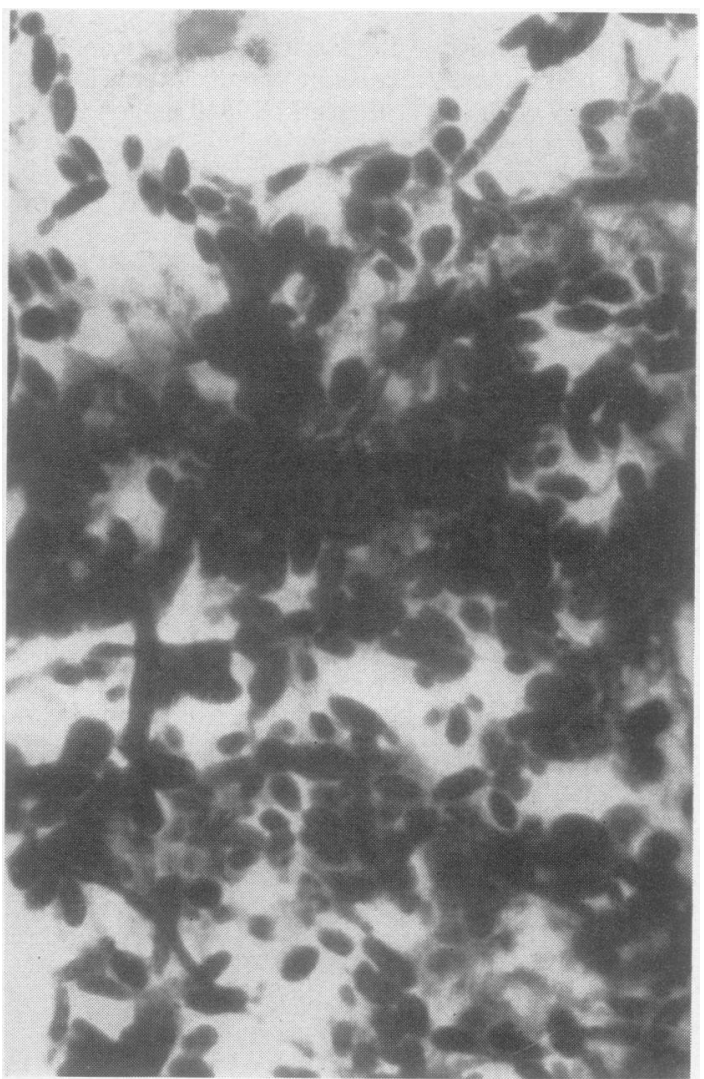

FIG. 2. Case 1. Microscopical picture of the gastric contents. Widespread massive occurrence of oval yeast cells and pseudomycelia. Small numbers of slender Gram-positive rods in some areas. Gram-stained preparation. $\times 1,200$.

CASE 2 T.O., a woman, born in 1914, after having had symptoms of duodenal ulcer for 13 years, on 12 March 1964 was subjected to gastrectomy (Billroth I). She had symptoms of gastric retention in the postoperative course but left hospital in a good condition on 31 March.

She returned on 27 April because of vomiting and symptoms of gastric retention. Radiological examination showed a slightly dilated residual stomach with retention of fluid. The barium did not pass into the duodenum until two hours after ingestion. She was treated with a tube after which the retention ceased and $x$-ray examination revealed a normal gastric remnant with a slightly narrowed stoma. The patient received no antibiotic or steroid therapy. 


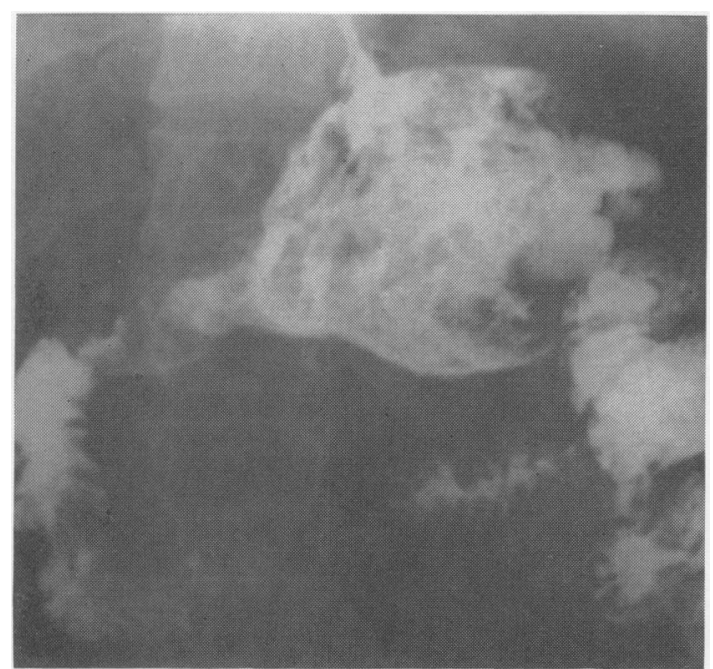

FIG. 3. Case 2. Bezoar-like mass in slightly dilated gastric remnant. Patent, though somewhat narrowed stoma. Prone position.

Because of continued vomiting a new $x$-ray examination was done four weeks later. This showed a slightly dilated gastric remnant now containing a sponge-like mass and a patent though still somewhat narrowed stoma (Fig. 3).

A narrowing of the anastomosis to about the size of a pencil was found at operation. Plastic repair of the stenosis was followed by a stormy postoperative course because of leakage. Microscopical examination of a biopsy specimen of the stomach taken at this operation showed signs of gastritis only. A sample was also taken of the gastric contents.

When last seen 10 months after the last operation, the patient felt well and $x$-ray examination showed a normal picture after a Billroth I resection. She has not so far consenter to stimulation with histamine.

Microbiological examination Samples of the gastric contents collected on three occasions after the first operation and at the second operation were examined microscopically and invariably showed masses of yeast cells embedded in mucous material (Fig. 4). Culture regularly yielded heavy growth of yeasts. Examination of the growth obtained on culture of the specimen taken at the last operation showed the yeasts to be Torulopsis glabrata. Culture for bacteria gave inconstant results. In the specimen obtained at the last operation the bacterial flora consisted mainly of coliform bacilli. On the earlier occasions, however, there were fairly large numbers of lactobacilli intermingled with small numbers of streptococci and aerobic spore-forming bacilli.

CASE 3 H.M., a man, born in 1916, had symptoms of peptic ulcer since September 1961. Radiological examination showed a gastric ulcer. Because of slow healing and frequent recurrences gastrectomy (Billroth I) was done on 15 November 1962. In January 1963, after about one month's freedom from symptoms, the patient returned complaining of daily vomiting, sometimes of food, sometimes of mucus. Radiological examination on 23 January 1963 showed a dilated residual stomach containing a bezoar-like formation, but good passage of the barium through the anastomosis. During the further course his symptoms varied, but were dominated by a feeling of epigastric tension, early feeling

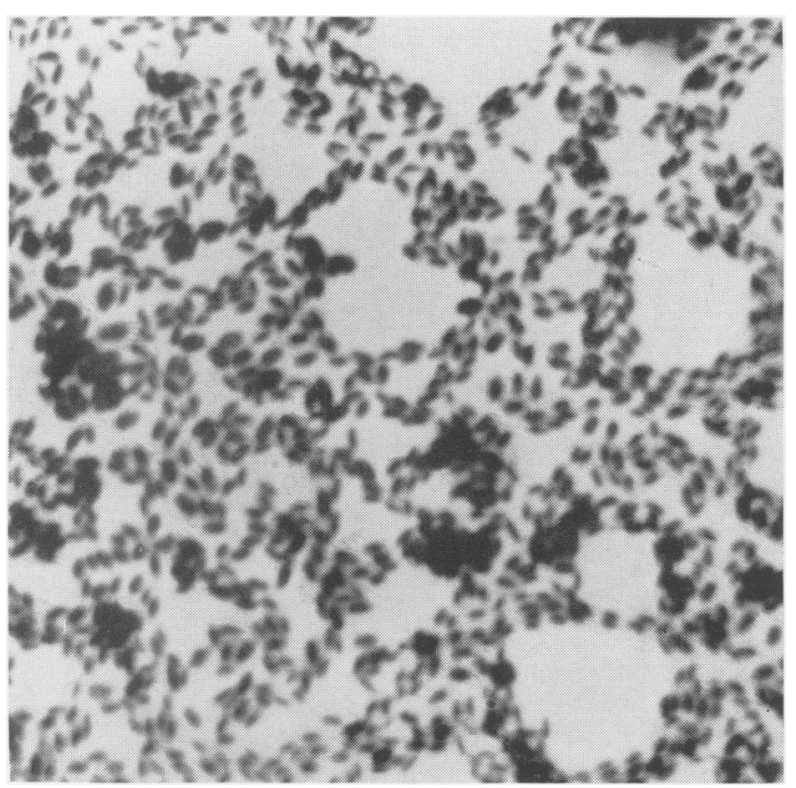

FIG. 4. Case 2. Microscopical picture of gastric contents obtained at operation. Numerous small oval cells embedded in mucous material. Culture grew Torulopsis glabrata.Gram-stained preparation. $\times 1,200$. 


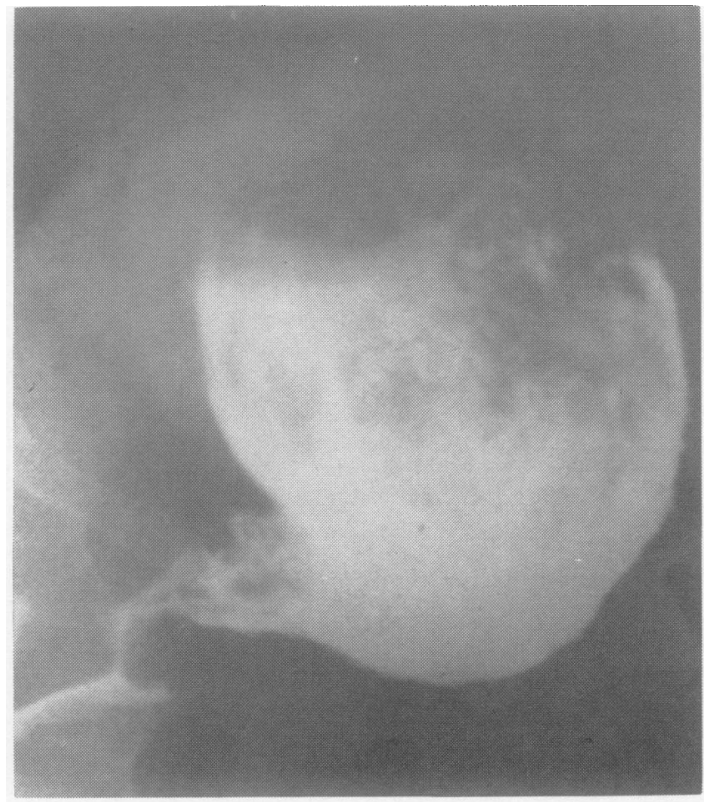

FIG. 5 a.

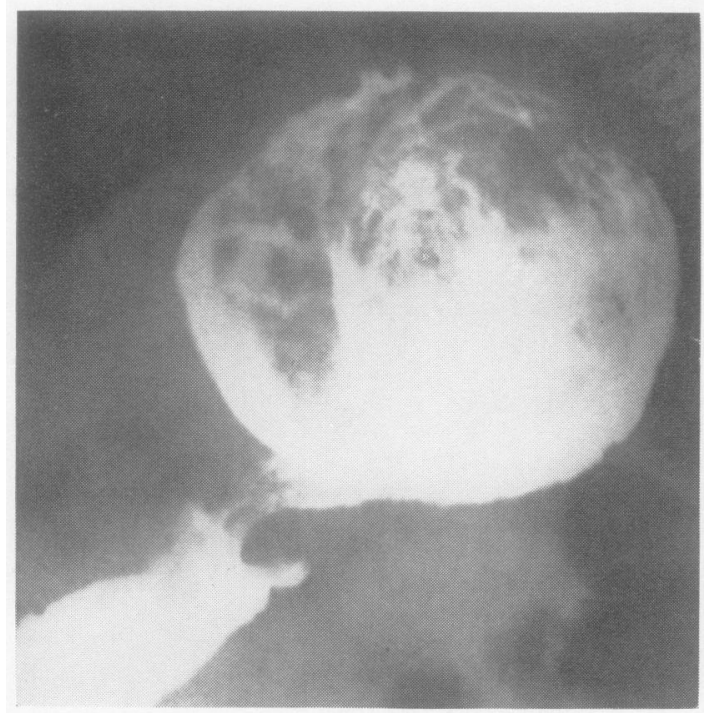

FIG. $5 \mathrm{~b}$.

FIG. 5. Case 3. Dilated residual stomach with bezoarlike formation. Unhindered passage through normal anastomosis. (a) standing position, (b) prone position. of fulness at meals, and vomiting. Repeated radiological examinations showed largely the same picture for about two years (Fig. $5 \mathrm{a}-\mathrm{b}$ ). Since the patient's symptoms did not respond to conservative treatment, surgical exploration was decided upon. On 3 December 1964 the patient was subjected to operation with transposition of a piece of jejunum between the gastric remnant and duodenum to improve drainage of the stomach, in the hope that this would give relief. The anastomosis was found to be functioning satisfactorily. Microscopical examination of a biopsy specimen from the gastric mucosa taken at the operation showed only mild inflammation. The postoperative course was uneventful.

On no occasion was the patient treated with antibiotics or steroids.

Examination of augmented histamine-stimulated secretion showed no free $\mathrm{HCl}$ but a total acidity of $118 \mathrm{c} . \mathrm{u}$.

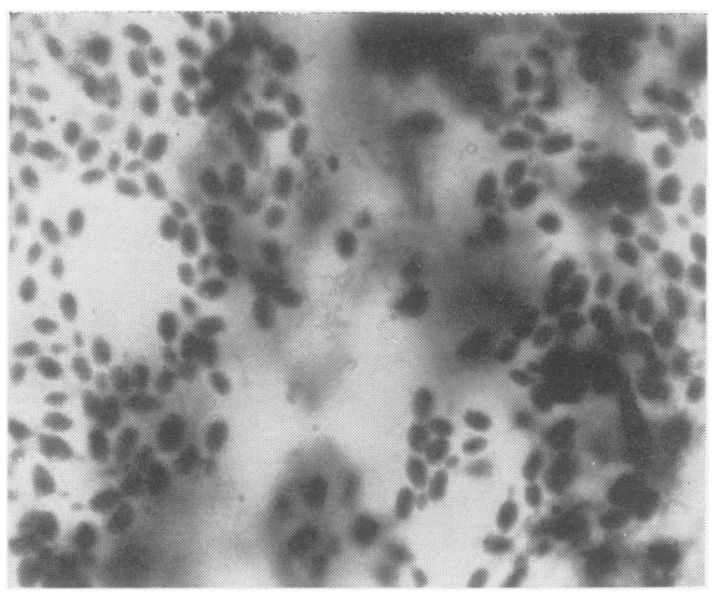

FIG. 6. Case 3. Microscopical picture of gastric contents. Gram-stained preparation showing typical budding and non-budding different-sized yeast cells. Culture in this case grew Candida albicans and Torulopsis glabrata. $\times 1,200$.

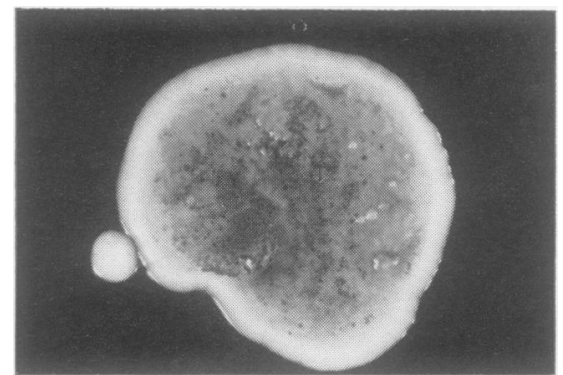

FIG. 7. Case 3. Coalescent growth of yeast colonies from the gastric contents dropped directly on Sabouraud glucose agar. Culture two days, roos: temperature. Actual size.

Microbiological examination Samples were taken on four occasions, once after gastric resection (Billroth I), once during, and twice after re-operation.

On microscopical examination the samples were found to contain abundant masses of yeast cells without pseudomycelia (Fig. 6). Cultures gave dense growth of yeasts 
(Fig. 7). On the first occasion the fungi were not classified. The bacterial flora consisted of streptococci and aerobic spore-forming bacilli. The samples taken during the operation showed abundant growth of Candida albicans intermingled with Torulopsis glabrata. Bacterial culture yielded a sparse growth of coliform bacteria. Two samples taken after operation showed the same two yeasts in the same quantities.

\section{DISCUSSION}

The previous history and the symptoms were largely the same in all three cases. Thus, the patients had been operated upon using the Billroth I technique and all had soon afterwards developed symptoms suggesting stenosis of the anastomosis. Only in one (case 2) had such narrowing actually occurred.

All three showed a typical radiological appearance, characterized by a sponge-like mass with the radiopacity of soft tissue in the residual stomach, though the stoma was patent. The mass did not mix well with the barium and simulated a bezoar or ingested food. However, repeated $x$-ray examinations after strict observation of the patients' food intake showed the same picture and aspiration of the gastric contents revealed that no food was left. In two of the cases (nos. 1 and 3) the residual stomach was markedly dilated.

In all three cases repeated microscopical examinations of the sample of the gastric contents showed abundant yeast cells. Various kinds of bacteria and mucous material were also present.

The massive growth of yeasts in the cases presented here sets them apart from other patients who have undergone gastric resection. Yeasts in smaller amounts together with various bacteria, which are not seen in most normal stomachs, are fairly common in the gastric contents after resection. But such a massive growth as that described in the foregoing has, as far as we know, never before been reported.

Candida albicans-was found in one case and Candida kruse i in another, both, however, in combination with Torulopsis glabrata. Torulopsis glabrata alone was seen in one case. None of the patients showed clinical evidence of yeast infection elsewhere, e.g., in the oral cavity or oesophagus.

Steroid therapy or extensive antibiotic treatment, which might have favoured a selective growth of fungi, was not given in any of the cases. There is no reason to suppose that treatment with benzylpenicillin for five days after the operation in case 1 had any important influence upon the development of fungal growth. Neither could other factors, such as endocrine disorders, malnutrition, cachexia, and previous radiotherapy, which sometimes pave the way for generalized fungal invasion, be demonstrated.

Microscopical examination of biopsy specimens of the gastric mucosa showed nothing remarkable.
In none of the patients was there any free $\mathrm{HCl}$.

The patients described thus showed the clinical picture of gastric retention after a Billroth I type of gastrectomy. There was a characteristic radiological appearance of a bezoar-like mass in the gastric remnant. In only one case was there any narrowing of the anastomosis. Microscopy and culture of the gastric contents revealed a massive growth of yeasts in a mucous material. It seems that such gastric contents may, owing to their space-occupying character, produce the symptoms described above.

The cause of the condition is obscure. It is possible that an altered gastric secretion after this type of resection, together with interference with gastric emptying, with or without stenosis, is the main aetiological factor.

These findings are now being followed up by a comprehensive clinical, radiological and microbiological investigation of patients without gastric disease, patients with gall-bladder disease, patients with unoperated gastric or duodenal ulcer, and patients operated upon according to Billroth I or II techniques because of peptic ulcer. The results of this investigation will be the subject of a future paper.

\section{SUMMARY}

Three cases are reported in which gastric resection according to the Billroth I operation was later followed by symptoms of stenosis of the anastomosis. Operation revealed a slight narrowing of the anastomosis in only one. Radiological examination showed a characteristic bezoar-like mass in the gastric remnant in all three cases. Gastric aspiration produced mucous material which on microscopical examination and culture was found to be swarming with yeasts.

It is possible that the aforementioned symptoms may be due to the space-occupying nature of the retained mucous mass crowded with yeast cells.

We are indebted to Dr. Åke Frisk, of Stockholms Stads Sjukhuslaboratorier, for kindly verifying our mycological diagnosis in case 1 .

\section{REFERENCES}

Beemer, A. M., Pryce, D. M., and Riddell, R. W. (1954). Candida albicans infection of the gut. J. Path. Bact., 68, 359-366.

Craig, J. M., and Farber, S. (1953). The development of disseminated visceral mycosis during therapy for acute leukemia. Amer. $J$. Path., 29, 601 .

Lewis, S. J. (1933). Moniliasis of the lungs and stomach. Case report with autopsy. Amer. J. clin. Path., 3, 367-374.

Lodder, J., and Kreger-Van Rij, N. J. W. (1952). The Yeasts. North Holland Publishing Co., Amsterdam.

Meixner, K. (1935). Ausgebreiteter Soor des Magens, eine Veräzung vortauschend. Dtsch. Z. ges. gerichtl. Med., 25, 51-60.

Rosen von Rosenstein, N. (1771). Underrättelse om barns sjukdomar och deras bote-medel. Wenneberg and Nordström, Stockholm.

Winner, H. I., and Hurley, R. (1964). Candida Albicans. Churchill, London.

Zalesky, N. (1864). Ein Fall von Soor im Magen. Virchows Arch. path. Anat., 31, 426. 